\title{
A INFLUÊNCIA DA MIGRAÇÃO PARA A (RE) ORGANIZAÇÃO DO ESPAÇO NAS PEQUENAS CIDADES NO TERRITÓRIO DO SISAL (1990 - 2014).
}

\author{
Tamires da Silva Brito; Onildo Araújo da Silva² \\ 1. Bolsista PIBIC/FAPESB, Graduanda em Geografia, Universidade Estadual de Feira de Santana, e- \\ mail: tam.tamires10@gmail.com \\ 2. Orientador, Departamento de Ciências Humanas e Filosofia, Universidade Estadual de Feira de \\ Santana, e-mail: fssilvafs@hotmail.com
}

PALAVRAS-CHAVE: Território do Sisal, Migração, Pequena Cidade.

\section{INTRODUÇÃO}

Esse texto sintetiza os resultados da investigação intitulada: A influência da migração para a (re) organização do espaço nas pequenas cidades do Território do Sisal (1990 2014). Nosso objetivo geral foi analisar como a dinâmica migratória interfere na (re) organização das pequenas cidades do Território do Sisal, analisando os condicionantes dos processos migratórios para a reorganização espacial. O Território do sisal é formado por vinte municípios, são eles: Araci, Barrocas, Biritinga, Candeal, Cansanção, Conceição do Coité, Ichú, Itiúba, Lamarão, Monte Santo, Nordestina, Queimadas, Quijingue, Retirolândia, Santaluz, São Domingos, Serrinha, Teofilândia, Tucano e Valente.

Trabalhamos sobre a luz dos censos de 1990, 2000 e 2010, e com a estimativa populacional para 2015. Os censos populacionais produzem informações imprescindíveis para a definição de políticas públicas e a tomada de decisões de investimento, sejam eles provenientes da iniciativa privada ou de qualquer nível de governo, e constituem excelente fonte de referência sobre a situação de vida da população nas pequenas cidades.

\section{METODOLOGIA}

Para o desenvolvimento dessa investigação realizamos uma revisão de literatura e construímos um referencial teórico. Também foi realizado um levantamento de dados secundários referentes à dinâmica da população, com ênfase para processos migratórios, em fontes como: Site do Instituto Brasileiro de Geografia e Estatística (IBGE), Superintendência de Estudos Econômicos e Sociais da Bahia (SEI), Instituto de Pesquisa Econômica Aplicada (IPEA), que compôs a segunda fase do nosso trabalho. A etapa seguinte concretizou-se com a aplicação de questionários. Tanto os dados secundários quanto os questionários foram tabulados e analisados, resultando na sua organização através de gráficos, quadros e tabelas, sendo esta a penúltima fase da investigação. A organização do processo e os resultados constituem o relatório final. 


\section{RESULTADOS E DISCUSSÃO}

Trabalhando os dados do IBGE (Instituto Brasileiro de Geografia e Estatística) podemos fazer uma análise comparativa entre os municípios. Com relação à população total (Tabela 1), podemos observar que nos municípios de Teofilândia, São Domingos, Retirolândia e Candeal ocorreu um pequeno declínio populacional comparando os censos de 1991, 2000 e 2010. Já os municípios de Queimadas, Monte Santo e Ichu, tiveram seu declínio populacional registrado no censo de 2010.

Ressaltamos que entre os 18 municípios pesquisados, apenas no município de Valente não constatamos declínio populacional nesse período. Vale lembrar que não encontramos dados referentes aos censos de 1991 e 2000 para o município de Barrocas, uma vez que o mesmo ainda não era emancipado e fazia parte do município de Serrinha (Lei Estadual $\mathrm{n}^{\circ}$ 7. 620 cria o município de Barrocas no ano de 2000). Nos municípios de Araci, Santaluz e Tucano ocorreu um crescimento considerável da população total ao longo da série.

Tabela 1. População total nos censos demográficos de 1991, 2000 e 2010 e estimativa de população total em 2015. Municípios do Território do Sisal. Estado da Bahia. Brasil. 1991-2015.

\begin{tabular}{|lcccc|}
\multicolumn{1}{r}{ Município } & Total & Total & Total & Estimativa \\
\hline Araci - BA & $\mathbf{1 9 9 1}$ & $\mathbf{2 0 0 0}$ & $\mathbf{2 0 1 0}$ & $\mathbf{2 0 1 5}$ \\
\hline Barrocas - BA & 45.341 & 47.584 & 51.651 & 56.370 \\
\hline Biritinga - BA & - & - & 14.191 & 15.770 \\
\hline Candeal - BA & 14.620 & 14.641 & 14.836 & 15.799 \\
\hline Cansanção - BA & 10.728 & 10.121 & 8.895 & 9.011 \\
\hline Ichu - BA & 30.903 & 31.947 & 32.908 & 35.235 \\
\hline Itiúba - BA & 8.596 & 5.593 & 5.255 & 6.311 \\
\hline Lamarão - BA & 34.403 & 35.543 & 36.113 & 38.492 \\
\hline Monte Santo - BA & 10.275 & 9.523 & 9.560 & 9.442 \\
\hline Nordestina - BA & 51.280 & 54.552 & 52.338 & 54.733 \\
\hline Queimadas - BA & 9.315 & 11.800 & 12.371 & 13.321 \\
\hline Quijingue - BA & 23.162 & 24.613 & 24.602 & 26.083 \\
\hline Retirolândia - BA & 23.958 & 26.376 & 27.228 & 28.655 \\
\hline Santaluz - BA & 11.300 & 10.891 & 12.055 & 13.319 \\
\hline São Domingos - BA & 30.634 & 30.955 & 33.838 & 36.915 \\
\hline Teofilândia - BA & 10.276 & 8.526 & 9.226 & 9.877 \\
\hline Tucano - BA & 21.570 & 20.432 & 21.482 & 23.011 \\
\hline Valente - BA & 46.618 & 50.948 & 52.418 & 55.777 \\
\hline \multicolumn{1}{c}{ Fonte: IBGE } & 17.830 & 19.145 & 24.560 & 27.906 \\
\hline & & & Elaboração Tamires Brito
\end{tabular}

Analisando a população urbana dos municípios da serie foco da pesquisa, podemos observar que o município de Valente apresenta um crescimento populacional urbano em mais de $100 \%$ em comparação aos três censos (gráfico 1). Por esse motivo escolhemos esse município para aplicação dos questionários, onde analisamos esse crescimento populacional urbano e relacionamos com $\mathrm{o}$ fenômeno da migração. Foram entrevistamos 31 residentes naturais do município. A seguir apresentamos um perfil desses residentes. 


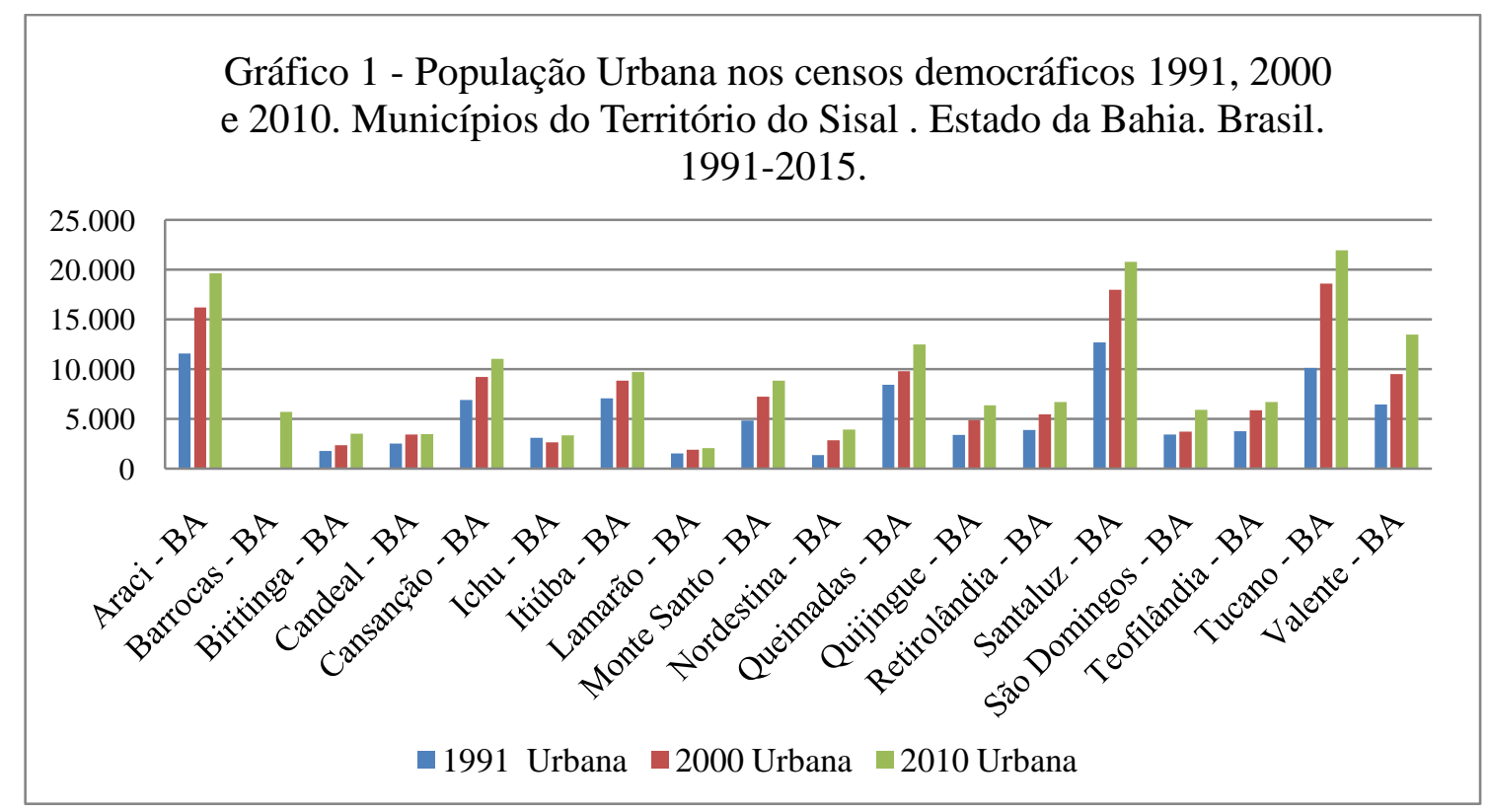

Fonte: IBGE

Elaboração Tamires Brito

Com relação ao sexo 14 são mulheres e 17 são homens. Em relação à profissão a uma diversidade muito grande, mas a que se destaca é a de lavrador. No que diz respeito à faixa etária dos residentes naturais do município de Valente, o destaque está entre 26-35 e 36-45 anos.

No questionário aplicado com os residentes naturais do município perguntamos a cada um deles se conhecia algum amigo/vizinho que veio morar no município. Dos 31 entrevistados 20 conhecem, ou seja, 65\% e 11 não conhecem, correspondendo assim aos $35 \%$ dos entrevistados.

Do total de residentes questionados $65 \%$ conhecem um vizinho ou amigo que migrou para Valente. Assim, perguntamos de onde essas pessoas vieram e $42 \%$ dos entrevistados não souberam informar o município. Vale lembrar que todo esse contingente populacional que veio morar no município de Valente é brasileiro, baiano e em alguns dos casos é do próprio Território do Sisal.

Além disso, perguntamos qual foi o motivo pelo qual esse amigo ou vizinho veio morar no município e 58\% dos entrevistados não souberam informar o motivo. Dos $42 \%$ que informaram um motivo, $13 \%$ declararam ser por motivo de trabalho, seguido de familiar (10\%) e busca de tranquilidade $(7 \%)$.

Perguntamos também se conheciam algum amigo/vizinho que foi morar em outro município e $87 \%$ disseram que sim, apenas $13 \%$ disseram que não. Em função do número tão expressivo de entrevistados que responderam sim, o nosso segundo passo foi então perguntar se eles saberiam informar para onde essas pessoas se mudaram. Nas respostas se destacaram as cidades de Florianópolis e Goiânia.

Também perguntamos aos nossos entrevistados residentes naturais de Valente se eles saberiam informar o motivo pelo qual essas pessoas saiam do município e $77 \%$ deles disseram que as pessoas saíram em busca de emprego. 


\section{CONCLUSÃO}

Entender a dinâmica populacional existente nas pequenas cidades do Território do Sisal não é algo fácil, no entanto, podemos utilizar alguns parâmetros para analisar essa dinâmica. Como bem diz Damiani (1996) "o fenômeno do povoamento não poderia ser compreendido sem as migrações", pois sabemos que esse processo é histórico. A discussão da migração no Território do Sisal tem um caráter estratégico na relação entre a dinâmica populacional e o processo de acumulação do capital, visto principalmente através da cadeia produtiva do sisal, pois, sua dinâmica populacional é um reflexo desse processo.

No entanto, não é apenas o processo da cadeia produtiva do sisal que propicia essa dinâmica, existem outros fatores nesse contexto, como revelam os dados colhidos nos nossos questionários, como motivos familiares, por exemplo. De forma geral, podemos dizer que é claro o crescimento populacional urbano em treze municípios do Território do Sisal, bem como a dinâmica da população e sua influência para a reorganização espacial nesses municípios.

Analisando os questionários aplicados no município de Valente, observamos que muitas pessoas saem de Valente para outros municípios em busca de emprego e melhores condições de vida. Mas, no caso de Valente, as pessoas migraram principalmente para Santa Catarina e normalmente deixam filhos, mulheres e família, trabalham por um tempo e retornam para o município de origem. Já em relação aqueles que migram para o município de Valente, o destaque também é para os motivos familiares.

\section{REFERÊNCIAS}

BACELAR, W. K. A.; Cidades Médias e Pequenas: Contradições, Mudanças e Permanências nos Espaços Urbanos. 94. ed. v. 1000. 238p. Salvador 2012.

CORREA, Roberto Lobato, GOMES, Paulo Cesar da Costa. Geografia: Conceitos e Temas. $13^{\circ}$ ed. Rio de Janeiro, 2010.

CORREA, Roberto Lobato. Região e Organização Espacial, São Paulo, 1991.

DOLLFUS, Olivier. O espaço geográfico. 4. ed São Paulo: Difel, 1982.

DAMIANI, Amélia Luisa. População e geografia, 2º ed. São Paulo, 1996.

SANTOS, Milton. A natureza do espaço: técnica e tempo; razão e emoção. 4. ed. 308 p. São Paulo: Hucitec, 1997.

SANTOS, M. Espaço e sociedade: ensaios. 2. ed. Petrópolis: Vozes, 1982

Instituto Brasileiro de Geografia e Estatísticas - IBGE, disponível em:

http://www.cidades.ibge.gov.br/xtras/home.php - Acessado várias vezes. 